\title{
Indicators to support an ecosystem approach to fisheries
}

\author{
Simon Jennings \\ Centre for Environment, Fisheries and Aquaculture Science, Lowestoft NR33 OHT, UK
}

\begin{abstract}
Indicators are needed to support the implementation of an ecosystem approach to fisheries (EAF), by providing information on the state of the ecosystem, the extent and intensity of effort or mortality and the progress of management in relation to objectives. Here, I review recent work on the development, selection and application of indicators and consider how indicators might support an EAF. Indicators should guide the management of fishing activities that have led to, or are most likely to lead to, unsustainable impacts on ecosystem components or attributes. The numbers and types of indicators used to support an EAF will vary among management regions, depending on resources available for monitoring and enforcement, and actual and potential fishing impacts. State indicators provide feedback on the state of ecosystem components or attributes and the extent to which management objectives, which usually relate to state, are met. State can only be managed if the relationships with fishing (pressure) and management (response) are known. Predicting such relationships is fundamental to developing a management system that supports the achievement of objectives. In a management framework supported by pressure, state and response indicators, the relationship between the value of an indicator and a target or limit reference point, reference trajectory or direction provides guidance on the management action to take. Values of pressure, state and response indicators may be affected by measurement, process, model and estimation error and thus different indicators, and the same indicators measured at different scales and in different ways, will detect true trends on different timescales. Managers can use several methods to estimate the effects of error on the probability of detecting true trends and/or to account for error when setting reference points, trajectories and directions. Given the high noise to signal ratio in many state indicators, pressure and response indicators would often guide short-term management decision making more effectively, with state indicators providing longer-term policy-focused feedback on the effects of management action.
\end{abstract}

Keywords ecosystem approach, fisheries management, fishing effects, indicators, power analysis

\author{
Correspondence: \\ Simon Jennings, Cen- \\ tre for Environment, \\ Fisheries and Aqua- \\ culture Science, \\ Lowestoft Laboratory, \\ Lowestoft NR33 OHT, \\ UK \\ Tel.: + $44(0) 1502$ \\ 524363 \\ Fax: + 44 (0) 1502 \\ 513865 \\ E-mail: s.jennings@ \\ cefas.co.uk
}

Received 11 Apr 2005 Accepted 20 July 2005
Introduction

Role of indicators

From management objectives to indicators

Reference points, trajectories and directions 


\section{Introduction}

Political commitments to an ecosystem approach to fisheries (EAF) are increasingly numerous (FAO 2003). An EAF is intended to ensure that the planning, development and management of fisheries will meet social and economic needs, but without jeopardizing the options for future generations to benefit from the full range of goods and services provided by marine ecosystems (FAO 2003). An EAF requires that managers take account of a wide range of fisheries impacts when setting objectives, and attempts to meet these objectives will need to be supported by reliable scientific advice and effective management decision making (Murawski 2000; Pope and Symes 2000; Link 2002; Sainsbury and Sumaila 2003; Browman and Stergiou 2004; Hall and Mainprize 2004; Pikitch et al. 2004). Indicators support the decision making process by (i) describing the pressures affecting the ecosystem, the state of the ecosystem and the response of managers, (ii) tracking progress towards meeting management objectives and (iii) communicating trends in complex impacts and management processes to a nonspecialist audience (Garcia et al. 2000; Rice 2000, 2003; Rochet and Trenkel 2003). Ecological, economic and social indicators are required to support an EAF, consistent with political aspirations for achieving ecological, economic and social sustainability (WSSD 2002).

The aim of this paper is to review recent work on the development, selection and application of indicators and to consider how they might support an EAF. I discuss relationships between indicators for an EAF and indicators for environmental reporting and propose a process for indicator selection. The review focuses on ecological indicators, although social and economic indicators are also part of an EAF.

\section{Role of indicators}

Indicators are defined as variables, pointers or indices of a phenomenon (Garcia et al. 2000) and are widely used for environmental reporting, research and management support (Spellerberg 2005). In the context of an EAF, the ways in which groups of indicators are selected for different purposes can be generalized by considering an ecosystem (or more realistically a spatial management unit) with components and attributes. For reporting and research, indicators are usually chosen to provide good coverage of the components and attributes, where components are defined as functional or species groups and attributes as properties of the components (e.g. Fig. 1). 'Good coverage' is usually achieved by selecting components and attributes that are considered to be representative of the ecosystem, as knowledge and resources will always be too limited to achieve comprehensive coverage. Several indicators may be needed to track the state of one component and attribute or one indicator may track the state of several components and attributes (Shin et al. 2005). As attributes may not be directly measurable, indicators can act as proxies for them (Fulton et al. 2004a,b).

To support an EAF, indicators need to track the state of components and attributes that may be adversely impacted by fishing. Progress towards an EAF will be fastest if a clear process for selecting these indicators is identified (FAO 2003; ICES 2005). Indeed, a focus on wide-ranging treatment of components and attributes, such as would be 


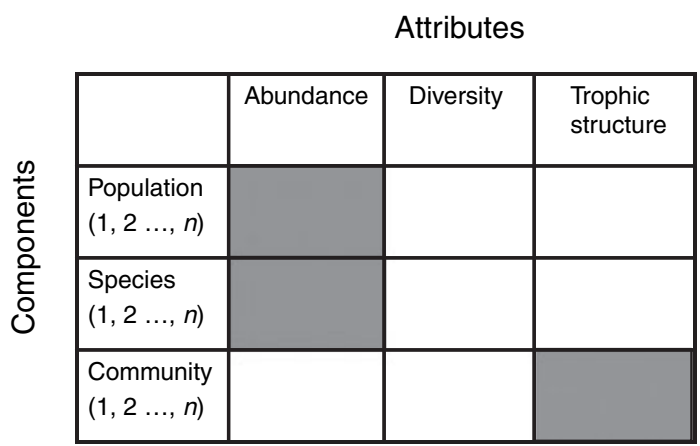

Figure 1 Matrix of example components and attributes that could be used to identify the indicators required for environmental reporting or management. For environmental reporting, indicators would be selected to cover all cells or groups of cells in the matrix. For management of fishing (and other human activities), indicators would be selected for cells where the component and attribute are significantly impacted by the human activity (examples shaded).

required for environmental reporting, has thus far resulted in debates about representativeness rather than a focus on the management of those fishing impacts most likely to compromise sustainability.

\section{From management objectives to indicators}

In developing a management system it is essential that societal/political aspirations can be translated into operational objectives to achieve sustainability (often termed strategic goals) (Sainsbury et al. 2000). Setting management objectives for an EAF precedes and informs the selection of indicators. Objectives are described in a range of policy documents relating to marine environmental management (Rice 2003; Sainsbury and Sumaila 2003).

In most management systems, at least two types of objectives are needed (Garcia et al. 2000; FAO 2003; Sainsbury and Sumaila 2003; O'Boyle et al. 2005). Higher level objectives relate to broad areas of policy commitment (e.g. reduce the rate of biodiversity loss). Lower level objectives are operational and relate to specific commitments at the scale of management (e.g. halt decline in the genetic diversity of Arcto-Norwegian cod Gadus morhua) (FAO 2003; ICES 2005; Fig. 2). Higher level objectives for an EAF will be consistent with existing policy commitments and further objectives would be added as policy and the EAF evolve. Setting higher level objectives is principally a societal issue, although science can provide commentary on the

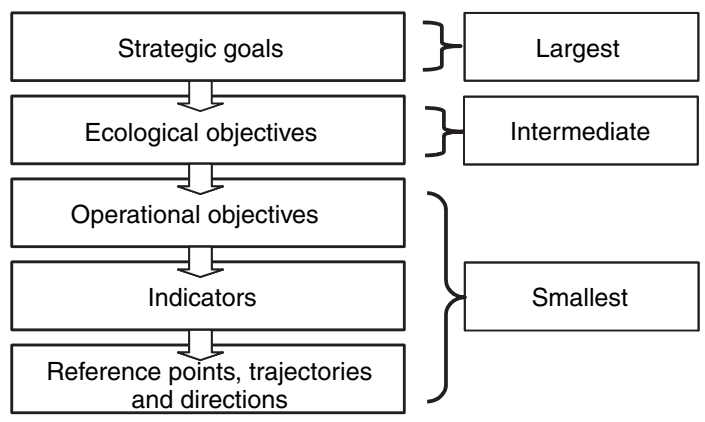

Figure 2 An example of a management framework in which indicators would be used and the spatial scales at which strategic goals, ecological objectives (higher level) and operational objectives (lower level) might be set. Modified from Sainsbury and Sumaila (2003) and ICES (2005).

consequences of setting different objectives and how to meet them (Sainsbury et al. 2000; ICES 2001). Objectives have the potential to accumulate very rapidly. For example, commitments made to achieve a significant reduction in the rate of biodiversity loss at the World Summit on Sustainable Development (WSSD 2002) potentially cover the variety, quantity and distribution of genes, populations, species, communities and ecosystems (G. Mace, unpublished) and fishing impacts all of these! For this reason, I will stress the importance of prioritizing impacts before selecting indicators to support objectives.

Fishing will impact different ecosystem components and attributes in different ways. Some impacts compromise the achievement of operational objectives for components and attributes, while other impacts may be detectable but are not necessarily undesirable. The first step in selecting indicators to support management is to identify the fishing impacts most likely to compromise the achievement of operational objectives and to rank them in terms of impact and likelihood of occurrence. A simple framework based on that proposed by FAO (2003) could be used for this purpose (Fig. 3). If other unsustainable impacts are identified, and relevant operational objectives do not exist, they should be set. Fishing impacts that currently compromise sustainability and thus the achievement of operational objectives have been extensively reviewed elsewhere, and include those on nontarget and bycatch species, benthic fauna and habitats, scavenging species, predator-prey interactions, nutrient recycling, community structure, 


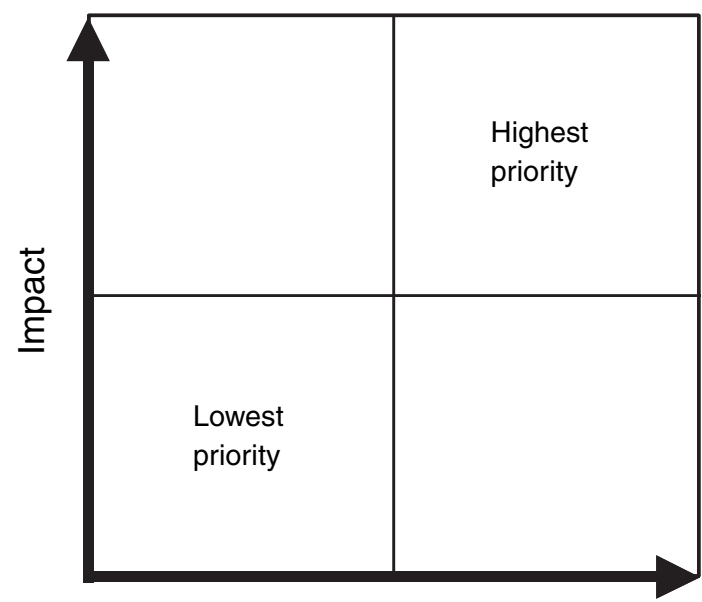

Likelihood

Figure 3 Qualitative risk assessment to identify high priority issues. After FAO (2003).

diversity (genetic, species, community, ecosystem) and ecosystem resilience and function (Gislason and Sinclair 2000; Kaiser and de Groot 2000; Sinclair and Valdimarsson 2003).

From a ranking of impacts most likely to compromise sustainability, state indicators relevant to each of the operational objectives, components and attributes can then be selected, with the number and complexity of indicators reflecting the resources available for management. One indicator or a series of indicators may be used to measure progress towards meeting each operational objective. Progress would be measured by comparing the recorded values or trends in the indicator with a reference point, trajectory or direction (FAO 2003).

\section{Reference points, trajectories and directions}

For indicators to support management decision making, the relationship between the current value and/or trend of the indicator and the value and/or trend of the indicator associated with meeting the operational objective needs to be known. The value and/or trend associated with meeting the operational objective can be a limit or target reference point, trajectory or direction. When indicators are used to guide management of target stocks, there is a tradition of setting reference points (FAO 1998). However, in other fields, a reference point may not be specified and a required trajectory or direction guides decision making.
As policy commitments and associated objectives relate to state, reference points, trajectories or directions to measure progress towards objectives are initially set for state indicators. The difference between the value of, or trend in, an indicator and a reference point, trajectory or direction is a measure of the performance of management (e.g. Sainsbury et al. 2000). Achievement of the reference points, trajectories or directions for state will, by definition, mean that operational objectives are met. Reference points that might support management decision making are (i) reference points for no impact, (ii) limit reference points for the values of indicators associated with serious or irreversible harm and (iii) target reference points for preferred values of the indicators (e.g. that reflect an optimal trade-off between ecological, social and economic sustainability) (Fig. 4). As indicator values include error, precautionary reference points may be used to guarantee a high (preferably specified) probability of avoiding a limit (FAO 1998; ICES 2001).

Reference directions can guide management when the value of an indicator is unsatisfactory or close to a limit, but when a target has not or cannot be defined (Link et al. 2002; Trenkel and Rochet 2003; Jennings and Dulvy 2005). Reference directions or trajectories might reflect the requirement to stop or reverse a decline in a given period. A recent example of a high level objective that could be supported by a reference trajectory is the World Summit on Sustainable Development commitment to achieve 'by 2010 a significant reduction in the current rate of biodiversity loss' (WSSD 2002).

The EAF is expected to provide greater long-term benefits to society if managers can meet targets. At present, however, there is more emphasis on avoiding limits. Thus biodiversity conservation focuses on avoiding extinction rather than seeking levels of abundance that maintain functional roles in food webs, and fish stock management often

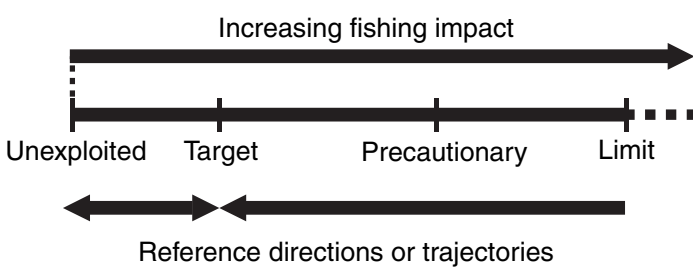

Figure 4 The relationship between reference points and reference directions and trajectories for an indicator of fishing impact. Modified from ICES $(2001,2005)$ and Jennings and Dulvy (2005). 
focuses on maintaining spawning stock biomass (SSB) above precautionary reference points rather than at levels associated with maximum long-term yield.

The authorities developing the European Marine Strategy have recently tied progress in relation to limits and targets to the concept of ecological status. Thus ecological status is defined as good when all targets are met, moderate when all precautionary limits are avoided and poor if any precautionary limits are exceeded (ICES 2005). This is a significant development as it encourages managers to achieve targets. Nevertheless, systems that mix targets and limits are likely to be unavoidable in practice because society may want to see abundant marine mammals but will be largely indifferent to near extinctions of many benthic invertebrates.

Reference points for unimpacted states can support comparative assessments of the impacts of fishing and management. Their use avoids the 'shifting baseline syndrome'; where baselines set with a short-term perspective represent an increasingly impacted state over time (Pauly 1995). The unimpacted state would not be a target in the context of EAF, except perhaps in reserves established solely for achieving this state. However, unimpacted reference points are used in the management of other human impacts, such as chemical pollution, where the targets for some materials would be zero (ICES 2005).

The setting of reference points, directions and trajectories is likely to generate significant controversy, as the values of reference points, directions and trajectories determine short-term costs to the fishing industry and long-term prospects for sustainability. Setting reference points, directions and trajectories for ecosystem state is likely to be even more difficult than setting single species reference points, notwithstanding the widespread acceptance of a precautionary approach (Rice 2003). Link (2005) has argued that the choice of reference points in many fields, including conventional fisheries management, can be arbitrary, although the reference points may be linked through models and/ or observations to a particular process. He therefore proposed 'first estimate' reference points for a number of state indicators for the Georges Bank, Gulf of Maine ecosystem. This approach was a positive step in promoting the debate necessary to further refine reference points. However, if 'first estimate' reference points are linked to decision rules that result in high short-term costs to fishers, then substantive challenges to these reference points are unlikely to be upheld until targets are linked to identifiable benefits, and limits are linked to the avoidance of serious or irreversible harm. Perhaps the challenges to 'first estimate' reference points will be a primer for the research that is needed to establish these links.

\section{Types of indicator}

Progress towards meeting operational objectives can be assessed using indicators that describe the state of components and attributes, but state indicators alone cannot support management decision making. This is because managers manage fishing, and can only change the state of the environment in predictable ways when the relationships between fishing pressure and state are known. If indicators of state can be reliably linked to indicators of pressure, then meeting reference points, directions or trajectories for pressure should correspond to meeting reference points, directions or trajectories for state. Actions taken by managers to modify pressure also need to be reported, as has been achieved through the use of response indicators. Indicators to support an EAF therefore need to provide information on the pressures affecting the component or attribute, the state of the component or attribute, and the response that society takes to control adverse pressure and achieve a desirable state. Several methods have already been proposed for classifying environmental management indicators on this basis, including the pressure state response (PSR) framework (Garcia and Staples 2000).

In the context of an EAF, pressure indicators will tend to be technical or ecological, state impacts ecological and responses technical or institutional. Examples of pressure indicators are fleet size, fishing mortality, fishing effort, catch rates or discard rates. Pressure is influenced by a range of factors including those that are the subject of social and economic objectives. Examples of state indicators are species abundance and mean body size. Most indicator development has thus far focused on state (ICES 2003; Fulton et al. 2004a; Rogers and Greenaway 2005). This focus probably reflects the important link between objectives and indicators of state. However, pressure and response indicators are essential to manage state and often have the desirable properties of ease of measurement and rapid response times. Examples of response indicators include most pressure indicators, expressed as 
rate of change, plus indicators of the capacity to support a response (e.g. capacity for decision support). The response indicator might measure management actions that mitigate, reduce, eliminate or compensate for the change in state. A response would usually affect the pressure (mitigation, regulation) but could directly modify state (rehabilitation) (Garcia et al. 2000).

While PSR is a convenient method of classification, more than one pressure, state or response indicator is often needed to support management. For example, to manage fishing impacts on fish populations requires that the relationship between fishing mortality (pressure) and fishing effort (pressure) is known, as well as the link between fishing mortality and abundance (state). It can also be difficult to define separate pressure and response indicators. Thus the proportion of an area impacted by trawling per unit time shows the pressure on a habitat, but also measures the response of management.

Frameworks more complex than PSR have been developed for classifying indicators, such as DPSIR (drivers, pressure, state, impact, response). In the DPSIR framework, human driving forces (D), such as the demands for food that are driven by population growth, exert pressure $(\mathrm{P})$ on the environment through more intensive extraction of natural resources thereby changing the state of the environment (S) by, for example, reducing the biomass of fishes. These changes in state have an impact (I) on society and the environment, such as fishery collapse, and society makes a response (R) by trying to influence the driving forces or pressure. In practice, relationships between DPSI and $\mathrm{R}$ are rarely clear and there are many complex feedbacks to consider (Garcia et al. 2000). Given the current institutional arrangements for marine environmental management, it is arguable whether DPSIR provides more clarity than PSR. In most circumstances the combination of pressure/response and state would be sufficient to provide meaningful guidance on progress towards objectives and to support management decision making.

Related pressure, state and response indicators must be measured at appropriate and related scales. For example, abundance at one small site will be a poor indicator of population abundance given the existence of distribution-abundance relationships, but high levels of fishing effort at one small site can affect population abundance. While single species managers have long defined the population as the correct scale for measurement of pressure, state and response, the scales for working with communities are poorly defined. For example, at large scales (ecosystems) size-based indicators show reliable responses to changes in rates of fishing mortality (Rice and Gislason 1996; Pope et al. 2004; Daan et al. 2005). However, when Piet and Jennings (2005) studied the response of these indicators to known management measures and spatial differences in fishing effort at smaller scales, the response was less reliable. Their comparison of the response of indicators in (i) areas subject to different levels of fishing effort and (ii) areas inside and outside a closed area where management measures led to changes in fishing effort over time, showed that the indicators would not provide good support for management at small temporal $(<5-10$ years $)$ and spatial (typically $<25-50 \times 10^{3} \mathrm{~km}^{2}$ ) scales.

Pressure, state and response indicators can be linked in various ways. In the simple case, a single pressure affects the state of a component and attribute and the pressure can be regulated by one response (Fig. 5a) Alternatively, several pressures acting additively or synergistically could influence state, and each pressure would have to be controlled by different responses (Fig. 5b). A single pressure could also affect several states and the pressure could be controlled with a single response (Fig. 5c). Finally, a single pressure could influence several states, but dealing with each change in state might require a different response (Fig. 5d). Given the range of potential linkages shown in Fig. 5, 1:1:1 $\mathrm{P}: \mathrm{S}: \mathrm{R}$ indicator frameworks are unlikely to support (a)

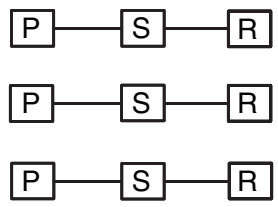

(c)

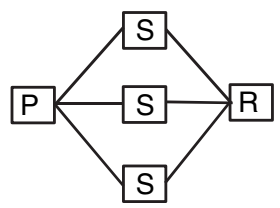

(b)

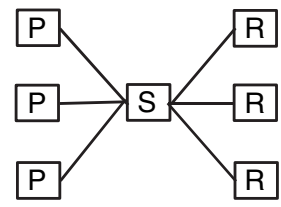

(d)

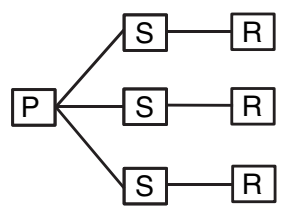

Figure 5 Possible relationships between pressure (P), state $(\mathrm{S})$ and response (R). Relationships (b-d) illustrate that indicators for $\mathrm{P}, \mathrm{S}$ and $\mathrm{R}$ are rarely expected to map one on one as in (a). 
an EAF. Thus a management framework might require several pressure and response indicators to measure progress towards meeting the target for one state indicator, or several response indicators to support a single pressure indicator (e.g. mortality on a migratory by-catch species may be inflicted by several fleets).

The intensity of fishing is measured with pressure indicators and changes in pressure lead to changes in state. For managers to achieve the state associated with meeting an operational objective, the link between pressure and state should be predictable, so that scientists can advise on the extent to which changes in response will modify pressure and state. With no understanding of this link, it is impossible reliably to manipulate human activity to achieve a desired state. Understanding and predicting the links between pressure, state and response has been a fundamental focus of single species management (Clark 1985; Hilborn and Walters 1992) and is a fundamental but often overlooked aspect of developing indicators to support an EAF (Daan 2005). This is despite the description, understanding and modelling of links between pressure and state being the focus of many studies of the ecosystem impacts of fishing, such as the impacts of trawling frequency on benthic invertebrate biomass and production (Duplisea et al. 2002), the impacts of fishing mortality on community metrics (Benoit and Rochet 2004; Pope et al. 2004), the impacts of mortality in long-line fisheries on the size of seabird populations (Weimerskirch et al. 1997), and the impacts of bycatch mortality on marine mammals (Caswell et al. 1999; Maunder et al. 2000) and non-target fishes (Pope et al. 2000).

\section{Selection of indicators}

There have been several attempts to list the desirable properties of indicators to support an EAF (Garcia et al. 2000; ICES 2001, 2003; Rice 2003; Rice and Rochet 2005). These lists have usually focused on the properties of state indicators. Garcia and Staples (2000) listed the ideal qualities of a range of ecological, social and economic indicators in terms of scope, policy relevance, timeliness, accuracy and precision, scientific validity, consensual basis, formal (legal) foundation, adequate documentation, specificity, multidimensionality, geographical resolution and technical feasibility. For ecological indicators of the state of Australian marine ecosystems, Ward (2000) did not adopt indicators if they related to issues that had only local relevance, were not elements of the environment of national importance and did not relate to widely spread effects. Key indicators were also rejected if there was no operational (or near operational) technology for implementation of routine measurements, routine implementation would be grossly expensive in relation to the benefits derived, or if no clear models were available to interpret the monitoring data in a way that would provide useful information for policy and management decisions. Indicators listed were classified as condition (state), pressure or response.

More recently, Rice and Rochet (2005) proposed properties of concreteness, theoretical basis, public awareness, cost, measurement, historical data, sensitivity, responsiveness and specificity, building on lists of ICES (2001, 2005) and J.C. Rice (unpublished data). These properties are summarized in Table 1. No indicator will, however, have all the properties listed in Table 1, and the properties will be given different levels of importance by different groups involved in the EAF. Rice and Rochet (2005) show how the importance of the criteria may depend on whether the users are technical experts and advisers, decision makers and managers, or a general audience. Similarly, Degnbol (2005) described how perspectives about indicators based on formal research-based knowledge and fishers knowledge differ, reflecting the different interests and scales of observation used by the two groups.

There has been little formal evaluation of the properties of proposed indicators and when occasional screening exercises have been conducted, many proposed indicators have fared poorly. For example, ICES (2001) screened potential state indicators against a list of criteria similar to those in Table 1 and found that few state indicators could usefully support management. For the criteria that required rigorous quantitative analysis, testing of the theoretical basis, sensitivity, responsiveness and specificity were poorly advanced in most cases.

The identification of state indicators is only one part of the overall process for selecting indicators to support an EAF. A possible full process is summarized in Table 2. Once state indicators have been selected (step 4), the identification of associated pressure and response indicators can follow. Understanding and predicting the links between pressure, state and response is fundamental to developing a management system to support the achievement of 
Table 1 Desirable properties of indicators to support an EAF (from ICES 2005 and Rice and Rochet 2005).

\begin{tabular}{|c|c|}
\hline Property & Description \\
\hline Concreteness & $\begin{array}{l}\text { Indicators should be directly observable and measurable rather than reflecting abstract properties } \\
\text { which can only estimated indirectly. }\end{array}$ \\
\hline Theoretical basis & $\begin{array}{l}\text { Indicators should reflect features of ecosystems and human impacts that (according to well-accepted } \\
\text { peer-reviewed scientific testing) are relevant to the achievement of objectives. They should be } \\
\text { based on well-defined and validated theoretical links. }\end{array}$ \\
\hline Public awareness & Public understanding of the indicator should be consistent with its technical meaning \\
\hline Cost & Indicators should be cost-effective because monitoring resources are limited \\
\hline Measurement & $\begin{array}{l}\text { Indicators should be measurable in practice and in theory. They should be measurable } \\
\text { using existing instruments, monitoring programmes and analytical tools available in the regions, } \\
\text { and on the time-scales needed to support management. They should have minimum or } \\
\text { known bias and signal should be distinguishable from noise }\end{array}$ \\
\hline Historical data & $\begin{array}{l}\text { Indicators should be supported by an existing body or time-series of data to aid interpretation of } \\
\text { trends and to allow a realistic setting of objectives }\end{array}$ \\
\hline Sensitivity & $\begin{array}{l}\text { Trends in the indicator should be sensitive to changes in the ecosystem state, pressure or response } \\
\text { that the indicator is intended to measure }\end{array}$ \\
\hline Responsiveness & $\begin{array}{l}\text { Indicators should be responsive to effective management action and provide rapid and reliable } \\
\text { feedback on the consequences of management actions }\end{array}$ \\
\hline Specificity & $\begin{array}{l}\text { Indicators should respond to the properties they are intended to measure rather than to other } \\
\text { factors and/or it should be possible to disentangle the effects of other factors from the } \\
\text { observed response }\end{array}$ \\
\hline
\end{tabular}

Table 2 A process for selecting indicators to support an EAF.

\begin{tabular}{ll}
\hline Step & Procedure \\
\hline 1 & $\begin{array}{c}\text { Set operational management objectives based on existing policy commitments and knowledge of potential } \\
\text { threats to sustainability (based on past and present experience and expectations for the future) }\end{array}$ \\
Identify the fishing impacts on components and attributes that may compromise each operational \\
objective (based on past and present experience and expectations for the future) \\
Rank fishing impacts from high to low probability that they will compromise the achievement of objectives \\
Based on step (3) and criteria for selecting good state indicators, identify state indicators (one or more) \\
for fishing impacts most likely to compromise each objective. Specificity, complexity and number \\
of indicators selected will reflect resources available for management \\
Identify/develop potential pressure and response indicators to describe the pressures and management \\
responses that influence the value of each state indicator
\end{tabular}


operational objectives. The process will be complex when synergistic and additive impacts occur, especially if the interacting impacts are due to sectors other than fisheries. If a management response is not, or cannot, be clearly defined by linking pressure, state and response, then there is little value in adopting a state indicator for management.

Following the identification of linked pressure, state and response indicators (Table 2), the next step is to set reference points, directions or trajectories for the state indicators associated with meeting operational objectives. Once these are set, it is necessary to confirm that all targets, directions or trajectories can be met, and all limits can be avoided, at the same time (Table 2). This may be achieved by empirical observation, through modelling the interrelationships among ecosystem attributes and components, and through the application of viability models. Viability models are attempts to describe possible evolutions of a dynamic system under uncertainty, compatible with constraints on state variables. These evolutions, defined by a 'viability kernel' satisfy the constraints at all times (Mullon et al. 2004; Cury et al. 2005). Constraints represent limits beyond which the necessary conditions for ecosystem wellbeing (avoidance of serious or irreversible harm) are not satisfied. At present, only a limited number of constraints and interactions have been considered using viability models, but algorithms to allow the consideration of more constraints and interactions are under development. Viability models focus on the 'undesirable' rather than the 'desirable' and may be more appropriate when management systems are based on avoiding limits. However, when there is the political and societal will to move towards target based management, ecosystem-based constraints can be expressed as limit reference points and considered simultaneously with target reference points (Cury et al. 2005).

When pressure, state and response indicators are in place, monitoring programmes must be identified or established to describe trends. As it is usually impractical and costly to change monitoring programmes frequently, programmes collecting data that can be reported, combined and analysed with the greatest flexibility are useful when several indicators may be based on the same data sets and when the indicators will evolve over time. Existing fisheries surveys are often strong in this regard, more so if they can be used as well funded platforms for assessing the status of other components or attributes of the marine environment (Callaway et al. 2002).

Rice and Rochet (2005) proposed a detailed process for indicator selection that could be considered as an elaboration of step 4 in Table 2. Their work was predicated on the recognition that each indicator has monitoring, evaluation and reporting costs, and that a few indicators selected according to clear criteria were less likely to overload decisionmaking systems than large numbers of relatively uninformative indicators. The Rice and Rochet (2005) process for indicator selection is to: (i) determine user needs (e.g. would indicators inform discussion or directly support decision making), (ii) develop a list of candidate indicators, (iii) determine screening criteria, (iv) score indicators against criteria, (v) summarize scoring results, (vi) decide how many indicators are needed - consistent with requirements for intercompatibility and keeping costs sensible, (vii) make the final selection of indicators and (viii) develop methods to report on the selection of indicators, including current state, dynamics of state, value judgement about state (or state in relation to targets and limits) and judgement about dynamics.

The complexity of indicators should depend on the resources available for management, although there will usually be a tradeoff between complexity and the extent to which links between pressure, state and response can be predicted. When few resources are available for management, simple indicators such as those proposed by Froese (2004) may be desirable. When resources are very limited, pressure indicators such as density of fishers or vessels per unit area of reef, will be easier and cheaper to use than state indicators (Johannes 1998). Reference points, directions or trajectories could be established from knowledge of pressurestate linkages in comparable fisheries. However, state would need to be reported in the longer term as it is unlikely that controls on pressure would be accepted without evidence that these helped to meet state-related operational objectives.

State indicators are likely to provide a less ambiguous response to fishing if they are more tightly linked to fishing impacts (Fulton et al. 2004b, 2005; Rice and Rochet 2005; Table 1). For example, mean size/mean maximum size and mean trophic level both respond to the effects of fishing on fish communities but mean size/mean maximum size is more tightly linked to fishing impacts than changes in trophic level because 
changes in the latter are a response to changes in the former. To elaborate, two factors affect the susceptibility of a population to the elevated rates of mortality. First, the rate of mortality. Second, the capacity of the population to withstand that mortality. Fishing is usually size-selective, both within and among species, so larger individuals and species suffer greater rates of mortality and have less capacity to sustain it. The net result is that exploited populations and communities contain relatively fewer large fish and mean size is reduced. Moreover, the proportion of large species in the community will fall. Both changes may be exacerbated by the 'release' of smaller prey species as their predators are reduced (e.g. Dulvy et al. 2004; Daan et al. 2005). These direct and indirect fishing effects are detected by the size-based metrics: (i) mean size (or mean slope of the size-spectrum) and (ii) mean maximum size. Both metrics have proved to be sensitive to fishing and relatively insensitive to climate change (but see Zwanenburg 2000), although it may take several years to detect a change in state following a change in pressure (Blanchard et al. 2005; Shin et al. 2005).

On average, larger species and individuals feed at higher trophic levels. As a result, changes in size structure will result in changes in trophic structure; so-called 'fishing down the food web' (Pauly et al. 1998). However, changes in size structure are generally a more valuable state indicator of fishing impacts because (i) relationships between size and trophic level within individual species are often stronger than relationships among species and (ii) trophic level is not a life-history trait that determines the response of a species to mortality, but a consequence of feeding relationships. The second point is demonstrated by the vulnerability of some of the largest bodied low trophic level animals, such as whales and sharks that feed on plankton and large parrotfishes that feed on algae, to fishing. As trophic level is not a measure of vulnerability and changes in mean trophic level are a consequence of changes in species and size composition, it is more logical to use size and species composition directly to measure the impacts of fishing (Jennings et al. 2002). If it is necessary to report trophic level as a state indicator, then trophic level is most usefully calculated as an output of analyses or sizebased models, for the range of body sizes where size and trophic level are related. This approach takes account of the fishing-induced changes in trophic level within and among species.
The overall process of indicator selection will ultimately link all indicators to fisheries impacts, management objectives and ecosystem components and attributes, such that the fields described in Table 3 could be completed for each state indicator. For each component and attribute there would be pressure, state and response indicators with associated reference points, trajectories or directions. Without this information the capacity to advise on fisheries management within an EAF is likely to be compromised. For state of the environment reporting, the minimum fields to be completed would be component, attribute and state indicator. The numbers and types of indicators that can be used to support an EAF will vary in different management regions, depending on resources available for monitoring and enforcement and the capacity of the fishery to impact the ecosystem. The sets of indicators used to support management are likely to be incomplete at the outset and evolve over time and as further resources and information become available.

\section{Evaluating the performance of indicators}

The data and knowledge required to evaluate the performance of indicators of ecosystem components and attributes are often extensive. One cost-effective way of evaluating performance is to use computergenerated data. Given that there is perfect knowledge about the trends, properties and sampling variance in these data, indicators that do not show desirable properties when based on these data are unlikely to show desirable properties with real world data. Management strategy evaluation (MSE) using computer generated data has already been used to assess the performance of single species

Table 3 Information needs for short-term development of an EAF supported by indicators

\begin{tabular}{cl}
\hline 1 & Importance of impact (rank number) \\
2 & Relevant operational objective (name) \\
3 & Component impacted (at scale of management) \\
4 & Attribute impacted (at scale of management) \\
5 & State indicator(s) (name and specification) \\
6 & Reference points, trajectories or directions \\
7 & for state indicator (values) \\
8 & Pressure indicator(s) (name and specification) \\
9 & Reference points, trajectories or directions \\
10 & for pressure indicator (values) \\
& Response indicator(s) (name and specification) \\
& Reference points, trajectories or directions for \\
\hline
\end{tabular}


management (Butterworth and Punt 1999; Sainsbury et al. 2000; Punt et al. 2001) and a similar process has recently been employed by Fulton et al. (2004b, 2005) to evaluate indicators for an EAF. Indicator performance was measured as the ability of indicators to detect or predict trends in attributes, where the true values were known from models.

Fulton et al. (2004b, 2005) evaluated the performance of a suite of candidate indicators, identified by Fulton et al. (2004a), for measuring the ecological impacts of fishing. Their approach is summarized in Fig. 6. First, they used a spatially resolved deterministic model, that tracked nutrient flow through major biological groups and captured the key behaviours of real systems, to describe ecosystem dynamics. Second, they used a sampling model that generated data with realistic measurement uncertainty (bias and variance), for a given sampling design (location and timing), to produce the data required to calculate values of a range of state indicators (e.g. for species, habitats, assemblages and ecosystem properties or processes). Simulated data were collected for different levels of fishing and fishing combined with other human activities. The performance of indicators derived from the data was assessed in terms of the indicators' capacity to track properties of interest (e.g. changes of public and legislative concern) and their ability to mimic attributes. The latter was assessed by plotting each indicator against each attribute

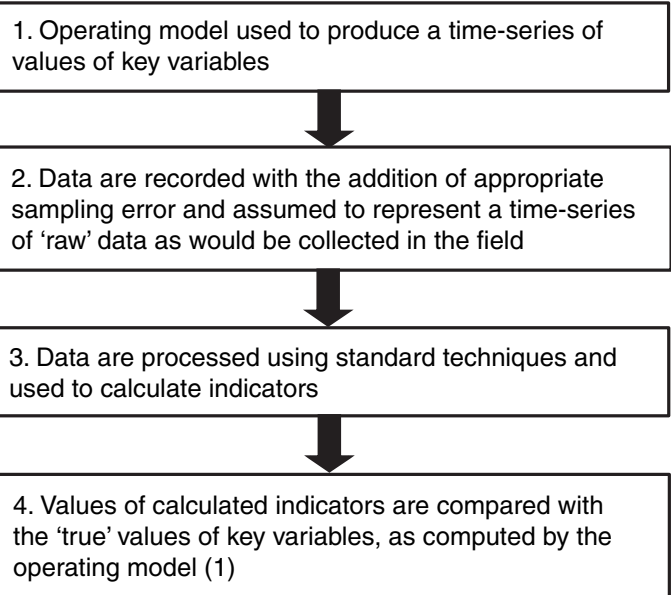

Figure 6 Steps in the simulation testing approach that Fulton et al. (2004b) used to assess the performance of state indicators. Model data generation and recording steps ( 1 and 2) were typically repeated many times to integrate across uncertainty in processes, functional relationships and parameters. and examining the correlation. Fulton et al. (2004b, 2005) identified a subset of indicators that tracked changes in a broad range of attributes, with interpretation robust to ecosystem type, exploitation pattern and level of data aggregation. State indicators for the following biological groups provided a good overall picture of impacts on the system (i) groups with fast turnover; (ii) groups targeted by fisheries; (iii) habitat defining groups; (iv) sensitive species with slow dynamics often close to the top of the food web. Indicators at the community level of organization performed best and indicators requiring a large range of data and incorporating an intermediate model in their calculation were prone to error that would mask an underlying signal.

\section{Power to detect trends}

Trends in indicators reflect noise and signal (Fryer and Nicholson 1993) and managers risk squandering credibility and resources if they respond to noise (Rice 2003; Fig. 7). If management action is to be predicated on signal, the influence of noise must be known when selecting indicators, designing monitoring programmes and setting reference directions and trajectories. Fulton et al. (2004b, 2005) used a sampling model that generated data with realistic
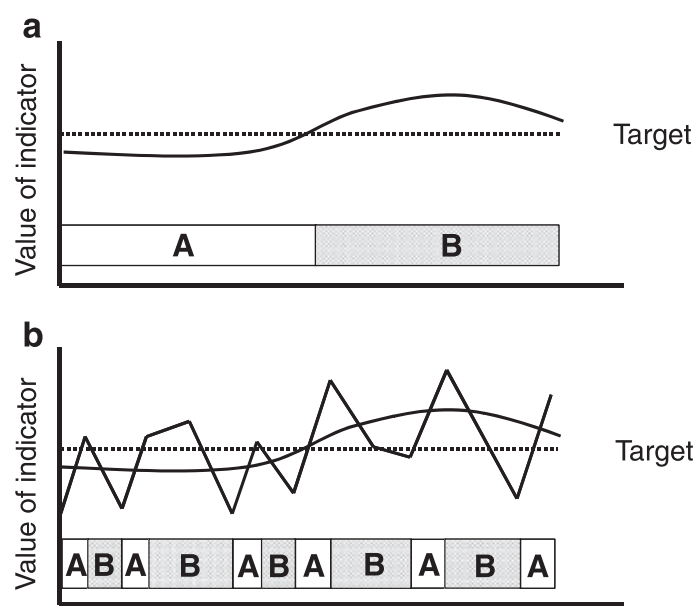

Time

Figure 7 Two hypothetical management responses (A or B) that depend on the value of an indicator in relation to a target reference point. In (a), the true value of the indicator is known and the trend in the indicator elicits a single management response. In (b), the true trend in the indicator is the same as in (a), but the value of the indicator is driven by noise as well as signal. As a result, there would be multiple changes in management response. 
measurement uncertainty (bias and variance) to assess the apparent responsiveness of state indicators to true changes generated by an operating model. Real data can also be examined to ask how noise affects the probability of detecting expected trends, using methods such as power analysis and signal detection theory (Gerrodette 1987; Peterman 1990; Nicholson and Fryer 1992; Rice 2003). The effects of noise on an indicator value can also be accounted for when setting reference points, by adjusting the location of the precautionary reference point in relation to the limit (Smith et al. 1993; FAO 1998).

\section{Power analysis}

Power calculations demonstrate whether indicators provide feedback to managers on the timescales over which progress in relation to objectives might be assessed. If power is low, and it takes many years of monitoring to detect a relevant trend, then the monitoring programme and/or indicator may need to be modified (Trenkel and Rochet 2003). When analysing trends in indicators, the conclusion that a true trend exists, when it does not, is a type 1 error. The conclusion that a trend is not occurring, when it is, is a type 2 error. If the probabilities of making type 1 and type 2 errors are $\alpha$ and $\beta$, respectively, power can be defined as $1-\beta$, the probability that a particular trend will be detected (Gerrodette 1987; Nicholson and Fryer 1992). Power depends on the magnitude and pattern of trend, the residual variance, statistical test, sampling scheme, acceptable power and the significance level of the test.

For the manager and society, there are different costs associated with making type 1 and type 2 errors. Thus the acceptable power and significance level used should depend on these potential costs (Di Stefano 2003). A type 1 error could lead to managers responding to noise rather than signal, with concomitant waste of scarce resources (Rice 2003). A type 2 error could lead to managers failing to identify a necessary management action (Taylor and Gerrodette 1993). Higher type 1 error rates are appropriate when the costs of type 1 errors are high. For example, when avoiding a limit associated with serious or irreversible harm, such as high extinction risk, higher type 1 error rates would be acceptable because the costs of type 1 errors (extinction) are lower than those of type 2 (failure to detect a real decline) (Maxwell and Jennings 2005). The converse might be true with an indicator of community structure and a target reference point, because falsely detecting a decline could lead to a costly management response while failure to detect a decline would not result in serious or irreversible harm (Nicholson and Jennings 2004).

Power analysis has been used to assess the power to detect trends in a variety of state indicators (Trenkel and Rochet 2003; Nicholson and Jennings 2004; Jennings and Dulvy 2005; Maxwell and Jennings 2005). For example, Nicholson and Jennings (2004) tested the power of a large-scale annual trawl survey (North Sea International Bottom Trawl Survey, IBTS) to detect trends in six state indicators for fish communities: mean length, mean weight, mean maximum length, mean maximum weight, slope of the biomass size spectrum and mean trophic level. Their analyses demonstrated that the power of the existing trawl survey to detect trends was generally poor. Thus pressure indicators would have best supported short-term management, with state indicators providing feedback on longer time scales.

For size-based fish community state indicators, power is strongly dependent on the range of size classes used to estimate the indicator value. The selection of different size classes can weight indicators to respond to the release of small fishes from predation, the depletion of larger individuals because of exploitation, or both (Dulvy et al. 2004; Daan et al. 2005). Such weightings may not be consistent over time because the differential vulnerability of larger species, within-population changes, predator-prey relationships and the effects of competition depend on contemporary rates of fishing mortality and the history of exploitation. Jennings and Dulvy (2005) investigated how the selection of different size ranges affected power to detect trends in a reference direction, using data from the North Sea IBTS. Mean individual mass decreased faster over time when smaller mass classes were included, but interannual variance was larger. For mean maximum mass of mature fish and the slope of the size spectrum, interannual variance was highest when the smallest or largest size classes were used in the calculation, and this affected power to detect trends (Fig. 8). The results demonstrate the value of power analysis in guiding indicator development.

When abundance cannot be estimated by alternate means, catch-per-unit-effort (CPUE) data are often proposed as a state indicator. The relationship between CPUE and true abundance is very sensitive to changes in distribution with abundance (Walters 


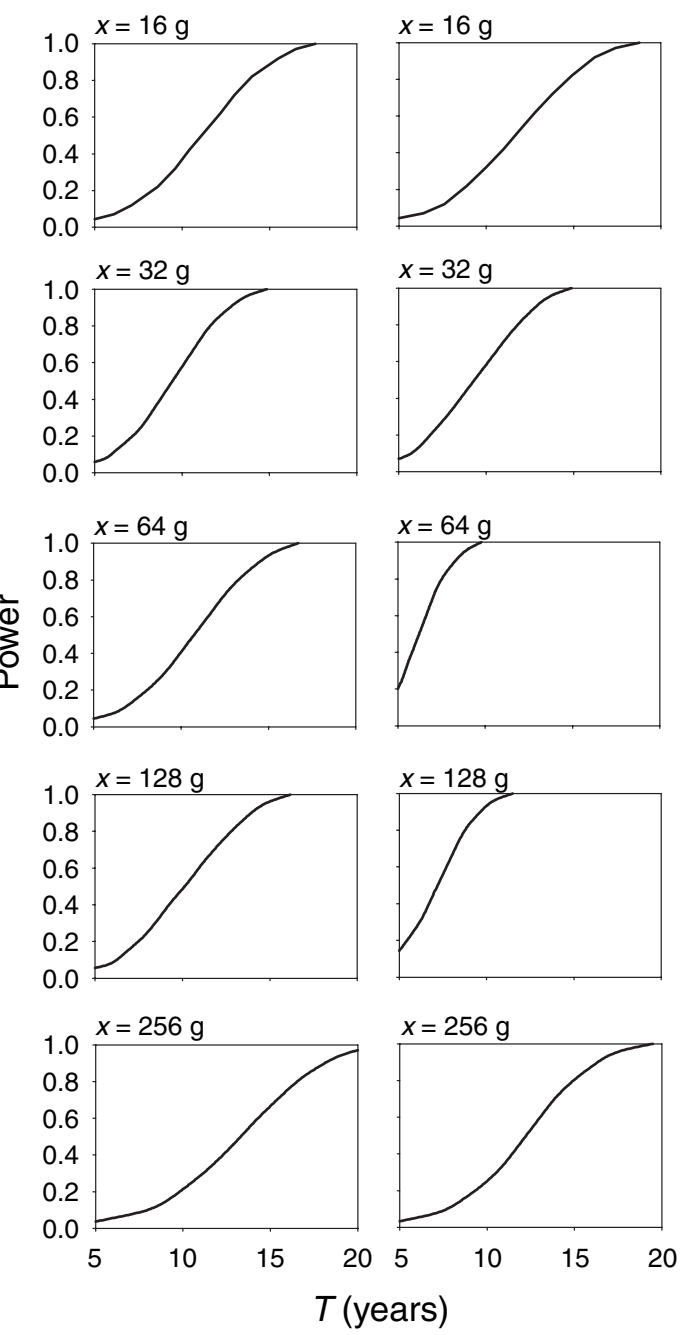

Figure 8 Power to detect future temporal trends (based on observations 1982-2000) in the mean mass (left) and mean maximum mass (right) of the mature component of the North Sea demersal fish community as a function of the number of years for which data are available and of the minimum body mass class $(x)$ included in the analysis (range $x-4096$ g). After Jennings and Dulvy (2005).

and Martell 2004). Maxwell and Jennings (2005) calculated the power to detect decline and recovery of bottom dwelling species that are vulnerable to fishing, based on CPUE data. Vulnerability was assumed to be determined by body size. The declines included rates of decline that met International Union for the Conservation of Nature and Natural Resources (IUCN) A1 criteria for 'Critically Endangered', 'Endangered' and 'Vulnerable' (Baillie et al. 2004). Recovery rates included the maximum predicted rate of recovery in the absence of density dependence (Myers et al. 1997). As extinction of a population results in serious and irreversible harm, type 1 error rates $>0.05$ were considered when calculating the power to detect declines. The survey rarely detected year-on-year decreases in adult abundance (as CPUE) of 50\% after 5 years. When $\alpha=0.05$, the power of the survey to detect year-onyear percentage decreases in abundance consistent with reference trajectories that would trigger IUCN listings (Baillie et al. 2004) was sometimes sufficient to identify 'Critically Endangered' species, but usually insufficient to identify 'Endangered' and 'Vulnerable' species over 10 years or three generations. To identify species as 'Endangered' and 'Vulnerable' would often require $>20$ years of monitoring data. When the power to detect reference trajectories that would lead to listing was recalculated for type 1 error rates of $\alpha=0.20$, the improvements in power were relatively small, but they were just sufficient to ensure that declines corresponding to "Critically Endangered' would be detected. If effective management action were taken, and the populations did recover, the time required to detect the maximum rate of increase in adult abundance ranged from 5.2 years to 5.9 years. These analyses usefully demonstrate the relatively low information content of CPUE data for these vulnerable species.

The aforementioned analyses show that power to detect expected trends in state indicators can be low, even if sampling designs are 'optimized' for the resources available. Conversely, measurements of pressure and response, such as direct measures of fishing effort as determined from satellite vessel monitoring data, can be precise and/or accurate. As a result, guidance for year on year management decision making may have to be based on pressure and response indicators, with changes in state assessed less frequently to confirm that pressure and response have affected state as predicted (Nicholson and Jennings 2004).

Power calculations can be made for linear and non-linear trends that might be used as reference directions or trajectories, but these trends tend not to capture the short-term signals observed in real data (e.g. year to year). This is because the variance estimates used in power calculations come from a statistical rather than ecological model. The reliance on a statistical model is a potential weakness of power analysis, but it may have little practical impact when consistent year on year trends are a feature of the reference trajectories or directions used to judge the success of management. Thus calculated power is the power to detect medium 
term societal expectations and medium term ecological change.

In power calculations, variance estimates from retrospective analyses are usually assumed to apply in future years. This assumption will be violated when fishing impacts and/or the environment change. For example, as fishing mortality rises, the size structure of a community may become more sensitive to annual recruitment events, leading to greater variance in a size-based community indicators (Shin et al. 2005). Conversely, when fishing mortality falls, variance may fall because effects of annual variations in recruitment will be buffered by the increasingly extended size and age structure of the community. Consequently, true power will be lower than predicted when fishing is increasing and higher than predicted when it is decreasing.

\section{Signal detection theory}

To assess the relationship between signal and noise in an indicator, Rice (2003) proposed the application of signal detection theory, where the relationship between real world events and the information provided by indicators is assessed using a simple matrix (Fig. 9), where: $1=$ hit- event occurred and the signal says something happened, $2=$ missevent occurred but it was indistinguishable from noise, 3 = false alarm - nothing actually happened but the signal says that something did and $4=$ true

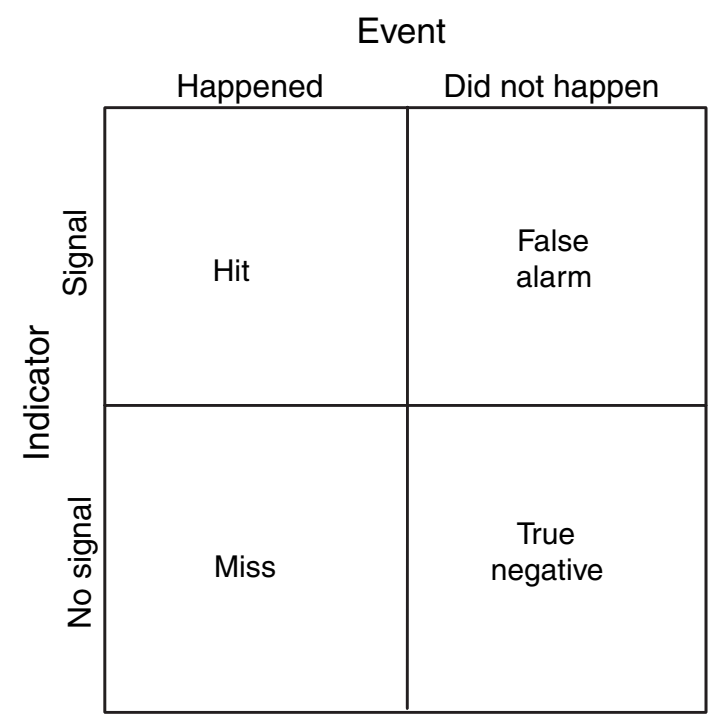

Figure 9 The matrix of possible relationships between real events and events recorded by an indicator. After Rice (2003). negative - nothing happened and there was only noise in the signal. A perfect indicator would give only hits and true negatives, but as indicator values contain more noise, so the probability of misses and false positives will increase. Misses and false alarms have different consequences. Costs of false alarms are borne by society and costs of misses by the ecosystem in the short-term and society in the longterm (Rice 2003).

Signal detection theory was applied by Piet and Rice (2005), when they assessed the performance of fisheries management advice using precautionary reference points. In their analysis they considered the performance of pressure (fishing mortality, F) and state (SSB) indicators independently and together, in relation to the precautionary reference points $F_{\mathrm{pa}}$ and $B_{\mathrm{pa}}$. This was a consequence of their being recorded on the same timescale (one year).

Piet and Rice (2005) compared advice in the assessment year with retrospective knowledge of stock status in the assessment year. The approach relied on the convergence of the stock assessment, where substantial uncertainty in SSB or F in the assessment year is reduced as catch and survey data accumulate in subsequent years. To adopt this approach they had to assume that the later estimates were correct. The possible scenarios they considered were: $1=$ hit, stock is below target SSB or fishing mortality above target $\mathrm{F}$ and advice is given to reduce fishing; $2=$ miss, stock is below target SSB or fishing mortality above target $\mathrm{F}$ and advice is for status quo or to increase fishing; $3=$ false alarm, stock is above target SSB and fishing mortality below target $\mathrm{F}$ and yet advice is given to reduce fishing; $4=$ hit, stock is above target SSB and fishing mortality below target $\mathrm{F}$ and advice is for status quo or increased fishing. They determined the proportion of hits and misses for each assessment year based on retrospective knowledge of stock status. When the authors examined the performance of a pressure (fishing mortality) and state (SSB) indicator simultaneously, the proportion of hits was the same as for the state indicator alone, but the proportion of misses was slightly lower. Using just the pressure indicator gave low rates of false alarm but high miss rates.

\section{Management decision making}

Indicators for components and attributes have to be linked to objectives and to an effective management process (Sainsbury and Sumaila 2003). Otherwise, 
to draw on an analogy of J.C. Rice (unpublished), indicators will allow you to see your fate more clearly but not to avoid it. The observed values and trends of indicators in relation to reference points, directions and trajectories determine the management actions to take. These management actions may be formalized, pre-determined and pre-negotiated, as is often the case in single-species management (e.g. if stock size $=x$, and fishing mortality $=$ $y$ then total allowable catch $=z$ ) (Gilbert et al. 2000; Sainsbury et al. 2000), or may be based on expert and/or political judgement. While formalized systems are often preferred, their existence does not guarantee that a proposed response is implemented, and scientific advice provided through a formal process is routinely modified by subsequent political judgement.

It is important that responses to changes in indicator values are graduated, to avoid systems that flip-flop between no restrictions and no opportunities (Rice 2003). In a fisheries context, for example, precautionary reference points have tended to trigger moderate regulation rather than the harsh and immediate action associated with violating limits (FAO 1998). Sainsbury et al. (2000) provide many examples of decision rules used in single-species management and how catch and fishing mortality would be modified in response to changes in biomass. Figure 10 shows how a series of gradated management responses from A (relatively weak) to $\mathrm{E}$ (very strong) might be linked to values of an indicator.

Management strategy evaluation uses simulation modelling to examine the performance of alternate management strategies, and is likely to be valuable in supporting the development of EAF, given the complexity of ecosystems and our limited capacity

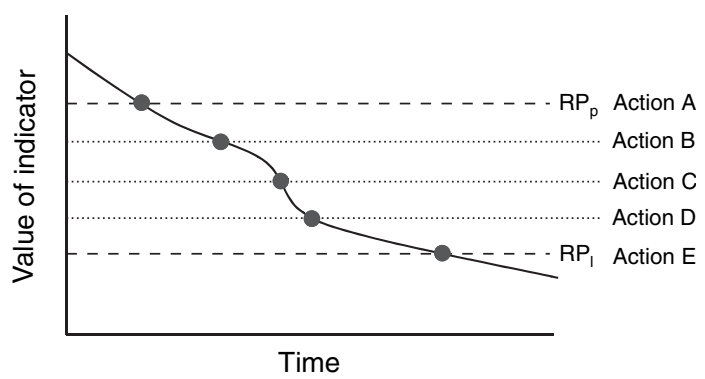

Figure 10 Gradated management action as the value of an indicator falls below a precautionary reference point $\left(\mathrm{RP}_{p}\right)$ and approaches a limit $\left(\mathrm{RP}_{1}\right)$. Management action ranges from relatively weak (A) to very strong (E). to understand their dynamics (Sainsbury et al. 2000; Fulton et al. 2004b). MSE methods simulate the whole management process. The qualities of alternate management strategies can then be compared, using performance measures derived from operational objectives (performance is typically expressed as difference between the value of an indicator and its associated reference point) and allowing for the propogation of error and uncertainty in the management process. The management strategies tested will typically include specifications for data collection, data processing and analysis, the use of analytical outputs in assessment, how the assessment determines any decision rules and how decisions may be implemented. MSE can be used to compare the effects of changes to specification in any part of the strategy. As previously discussed, Fulton et al. (2004b) are already making some significant progress in this field.

\section{Combining indicators to assess progress in relation to objectives}

State indicators vary in their specificity and the scale at which they can be applied. In many cases, state indicators apply to components and attributes at relatively small spatial scales, while the political process will set strategic goals and higher level management objectives at larger spatial scales. Hierarchies of indicators would support policy and management and help to assess progress in relation to objectives at many scales. A well-designed hierarchy of indicators might ensure (i) that high level indicators can be systematically 'unpacked' to identify where local management action is needed; (ii) that involvement in management at all scales and in all regions supports the achievement of strategic societal goals and (iii) that monitoring and management are co-ordinated at different spatial scales. Hierarchies of indicators can help to place the assessment of the effectiveness of an EAF on par with assessments of the success of managing other sectors as part of an ecosystem approach. Perhaps more importantly, they provide a method by which fisheries indicators can directly and meaningfully contribute to general state of the environment reporting on ecosystem components and attributes at a range of levels and scales.

Table 4 gives examples of indicator hierarchies for state and pressure indicators. In the first example, the state indicator for the population 
Table 4 Examples of hierarchies of state and pressure indicators. For the state indicator (a), SSB is spawning stock biomass and $B_{\mathrm{pa}}$ is a precautionary limit for spawning stock biomass (SSB). For the pressure indicator (b), the example relates to the proportion of vulnerable habitat types impacted by bottom trawling.

\begin{tabular}{|c|c|c|c|}
\hline Level of objective & Scale & Indicator & Target \\
\hline \multicolumn{4}{|l|}{ (a) State } \\
\hline 1 (e.g. higher) & All species & $\begin{array}{l}\alpha \text { species for which the SSB } \\
\text { of all populations is }>\mathrm{SSB}\end{array}$ & $100 \%$ \\
\hline 2 (e.g. higher) & Species & $\alpha$ populations where SSB $>B_{p a}$ & $100 \%$ \\
\hline 3 (e.g. operational) & Population & SSB & $>B_{\mathrm{pa}}$ \\
\hline \multicolumn{4}{|l|}{ (b) Pressure } \\
\hline 1 (e.g. higher) & Pan regional & $\begin{array}{l}\alpha \text { region where } 100 \% \\
\text { habitats impacted }<x \%\end{array}$ & $100 \%$ \\
\hline 2 (e.g. higher) & Region & $\alpha$ impacted $<x \%$ & $100 \%$ \\
\hline 3 (e.g. operational) & Subregion & $\alpha$ impacted & $x \%$ \\
\hline
\end{tabular}

supports management of the population, while the state indicators for 'species' and 'all species' provide overviews of population status that would be relevant to assessing progress in relation to higher level objectives, but can be unpacked to the population level when management action is required. In the second example, the subregional pressure indicator allows for the pressures leading to local changes in the state of habitat to be managed, while at the regional and pan-regional scale the indicator provides a measure of the extent to which pressure might compromise the achievement of higher level objectives. Any process for aggregating indicators should avoid the risk that relevant good and bad trends will be cancelled and that the value of the higher level indicator will be not be informative about local progress towards management objectives.

Targets should be compatible at different levels in an indicator hierarchy. One feature of combining indicators as proposed is that a target reference point can be set at higher levels when only reference directions can be set at lower levels. This may be useful when higher level indicators are used for policy communication.

When combining indicators, approaches that weight lower level indicators in relation to their perceived importance are often proposed; such that the values of more important indicators will have greater influence on the value of higher level indicators. An example is the weighting of climate change gases in relation to their contribution to global warming. In practice, I see little value in adopting this approach because weighting has effectively occurred when issues are prioritized for indicator development and managers will also weight informally, based on their experience and judgement. Rather, I consider that it is preferable for managers to work down the hierarchy of indicators until the impact causing the target to be missed is identified. The extent to which the target is missed and the risk associated with missing the target would then determine the management action.

One alternative to the hierarchy of indicators proposed here is the 'headline' indicator approach, where a single headline indicator of perceived importance is reported but a wider range of indicators are used to support decision making. 'Headline' indicators can be better for public communication than high-level indicators based on a hierarchy, but can also lead to managers focusing on the achievement of reference points, directions or trajectories for the headline indicator, rather than improving the overall state of the ecosystem.

\section{Discussion and conclusions}

Taking account of the ecosystem effects of fishing and meeting high level policy commitments such as those agreed at the World Summit on Sustainable Development (WSSD 2002) clearly imply greater reductions in fishing effort than would be required to meet single species objectives, particularly in mixed fisheries where vulnerable species are taken as bycatch (Hilborn 2004). Thus effective implementation of an EAF will not be straightforward, and will be compromised by most of the same issues that led to ineffective single species management, notably the difficulty of meeting social, economic and ecological objectives simultaneously when the short-term costs of doing so are very high (FAO 2002). For this reason, the debates over setting reference points, trajectories or directions, and taking management action, will still be long and difficult and heavily influenced by short-term economic and social concerns. Moreover, many of 
the hard lessons learnt about risk and precaution in a single-species context (Rosenburg and Restrepo 1994; FAO 1995; Patterson et al. 2001) will also apply to the EAF.

Policy commitments to an EAF are now widespread, and tending to run ahead of the science required to operationalize the approach (Fulton et al. 2005; Rice and Rochet 2005). The need to develop suites of indicators to support the EAF and support management decision making is well recognized (Garcia and Staples 2000), but with a few notable exceptions (Fulton et al. 2004b) progress has been quite limited because scientists working on specific problems may not be clear about the management frameworks in which indicators can be used. Here, it is proposed that indicators should guide the management of fishing activities that have led to, or are most likely to lead to, unsustainable impacts on ecosystem components and attributes.

In a management framework supported by pressure, state and response indicators, the relationship between the value of an indicator and a reference point, reference trajectory or direction provides guidance on the management action to take. As pressure and response indicators can link to state indicators in many ways, a management framework might require several pressure and response indicators to measure progress towards meeting the target for one state indicator, or several response indicators may be required to support a single pressure indicator. Values of pressure, state and response indicators may be affected by measurement, process, model and estimation error and thus different indicators, and the same indicators measured at different scales and in different ways, will detect true trends on different timescales.

When a suite of indicators has been selected, then reference points, trajectories and directions and associated management actions have to be agreed. Despite the prioritization of impacts and indicators, risk is most likely to be managed across all indicators in the early stages of adopting an EAF (Rice and Rochet 2005). This will often favour an approach where more management concern is focused on target stocks, with management action being modified to account for ecosystem concerns if reference points, directions or trajectories for ecosystem indicators are not met (Jennings and Dulvy 2005). Methodologies to achieve this for some components and attributes are already well developed (Maunder et al. 2000; Sainsbury et al.
2000). Only if there is a continued increase in the societal/political weighting given to ecosystem issues will the EAF start to mature outside existing strongholds (Witherell et al. 2000), and managing risk for ecosystem components or attributes will become as important as managing risk for target stocks (Jennings 2004). In the meantime, and consistent with the strategic goals of the EAF, managers would benefit from receiving decision tables that describe the expected status of target stocks in relation to reference points, alongside the expected status of various ecosystem components and attributes, for a range of management options. Such tables, especially when extended to incorporate the economic or social consequences of changes in components or attributes, will allow managers to assess tradeoffs between ecological, economic and social sustainability. Of course, decision tables will not make difficult choices any easier, but at least they ensure that choices are informed.

Another important step in developing indicators to support an EAF is to better predict more of the causal links between pressure, state and response. Such work builds comfortably on existing progress in understanding the ecosystem effects of fishing (Gislason and Sinclair 2000; Kaiser and de Groot 2000; Sinclair and Valdimarsson 2003), and the focus of much of the work will be the same as the focus of single species work; to link the size, power, days at sea, areas of operation and gears used by fleets (all of which can be managed), plus other changes in the environment, to changes in state. It is also necessary to further develop methods for identifying which reference points, trajectories and directions can be achieved simultaneously, and for the rigorous testing of indicator performance (Fulton et al. 2004b, 2005). Moreover, scientists should routinely assess the timescales on which indicators provide reliable information to managers, and managers should be guided by this knowledge when setting timebound objectives.

Given the difficulties associated with measuring short-term trends in the state of many ecosystem components and attributes, it is likely that managers will have to rely on pressure indicators for year to year guidance, with state being measured less frequently to determine whether progress towards operational objectives is adequate. However, a balance must be achieved between the reporting intervals for pressure and state indicators. Pressure indicators may provide good short-term guidance for managers because they can be precisely meas- 
ured, but over-emphasizing the apparent importance of pressure indicators should be avoided because society will ultimately judge the success of management in terms of state. Only if state is shown to respond to pressure will it be possible to justify the potential short-term social and economic costs of management measures.

Finally, I hope this review has clarified possible relationships among indicators for environmental reporting and management. For environmental reporting, indicators need to provide good coverage of ecosystem components and attributes, whether or not changes in these components and attributes can be attributed to manageable human impacts and whether or not associated pressure indicators are sought. For an EAF, indicators need to track the state of components and attributes that are adversely impacted by fishing, with priority given to the impacts that are most likely to be unsustainable. This approach will support effective short-term progress towards an EAF, given that knowledge and/or management resources are always limited.

In the longer term, methods of assessing the combined impacts of the environment, fishing and other sectoral activities on the ecosystem are likely to evolve. This suggests that indicators currently used for environmental reporting will provide information that feeds directly into the EAF as well as supporting exploratory analysis. The components vs. attributes matrix presented here can readily be adapted to allow for this evolution, with some indicators providing direct management feedback and others providing information to support assessment.

\section{Acknowledgements}

This work was funded by the UK Department of Environment, Food and Rural Affairs (projects M0729 'Assessing the abundance, distribution and vulnerability of rare and declining species impacted by fisheries' and M0731 'Development and testing of ecological indicators and models to monitor and predict the ecosystem effects of fishing'), the US National Science Foundation (through SCOR-IOC Working Group 119) and the European Commission (INDECO). I am very grateful to members of SCORIOC Working Group 119 (Cury and Christensen 2005), the ICES Working Group on the Ecosystem Effects of Fishing Activities, the ICES Advisory Committee on Ecosystems, and especially to Jake Rice, Marie-Joëlle Rochet and Stuart Rogers, for lively and informative discussions that helped to form and clarify my views on the role management indicators. Beth Fulton kindly provided unpublished CSIRO project reports on indicators and Jason Link and an anonymous referee made useful and challenging comments that helped to improve the manuscript.

\section{References}

Baillie, J.E.M., Hilton-Taylor, C. and Stuart, S.N. (2004) 2004 IUCN Red List of Threatened Species: A Global Species Assessment. IUCN Publications Services Unit, Cambridge.

Benoit, E. and Rochet, M.-J. (2004) A continuous model of biomass size spectra governed by predation and the effects of fishing. Journal of Theoretical Biology 226, 9-21.

Blanchard, J.L., Dulvy, N.K., Jennings, S., Ellis, J.E., Pinnegar, J.K., Tidd, A. and Kell, L.T. (2005) Do climate and fishing influence size-based indicators of Celtic Sea fish community structure? ICES Journal of Marine Science 62, 405-411.

Browman, H.I. and Stergiou, K.I. (2004) Perspectives on ecosystem-based approaches to the management of marine resources. Marine Ecology Progress Series 274, 269-303.

Butterworth, D.S. and Punt, A.E. (1999) Experiences in the evaluation and implementation of management procedures. ICES Journal of Marine Science 56, 985-998.

Callaway, R., Alsvåg, J., de Boois, I. et al. (2002) Diversity and community structure of epibenthic invertebrates and fish in the North Sea. ICES Journal of Marine Science 59, 1199-1214.

Caswell, H., Fujiwara, M. and Brault, S. (1999) Declining survival probability threatens North Atlantic right whale. Proceedings of the National Academy of Sciences of the United States of America 96, 3308-3313.

Clark, C.W. (1985) Bioeconomic Modelling and Fisheries Management. Wiley, New York.

Cury, P.M. and Christensen, V. (2005) Quantitative ecosystem indicators for fisheries management. ICES Journal of Marine Science 62, 307-310.

Cury, P.M., Mullon, C., Garcia, S.M. and Shannon, L.J. (2005) Viability theory for an ecosystem approach to fisheries. ICES Journal of Marine Science 62, 577-584.

Daan, N. (2005) An afterthought: ecosystem metrics and pressure indicators. ICES Journal of Marine Science $\mathbf{6 2}$, 612-613.

Daan, N., Gislason, H., Pope, J.G. and Rice, J.C. (2005) Changes in the North Sea fish community: evidence of the indirect effects of fishing? ICES Journal of Marine Science 62, 177-188.

Degnbol, P. (2005) Indicators as a means of communicating knowledge. ICES Journal of Marine Science 62, 606611. 
Di Stefano, J. (2003) How much power is enough? Against the development of an arbitrary convention for statistical power calculations. Functional Ecology 17, 707709.

Dulvy, N.K., Polunin, N.V.C., Mill, A.C. and Graham, N.A.J. (2004) Size structural change in lightly exploited reef fish communities: evidence for weak indirect effects. Canadian Journal of Fisheries and Aquatic Science 61, 466475.

Duplisea, D.E., Jennings, S., Warr, K.J. and Dinmore, T.A. (2002) A size-based model to predict the impacts of bottom trawling on benthic community structure. Canadian Journal of Fisheries and Aquatic Science 59, 1785-1795.

FAO (1995) Precautionary approach to fisheries. Part I: Guidelines on the precautionary approach to capture fisheries and species introductions. FAO Fisheries Technical Paper No. 350/1, 52 pp.

FAO (1998) A short review of precautionary reference points and some proposals for their use in data-poor situations. FAO Fisheries Technical Paper No. 379, 30 pp.

FAO (2002) Report and documentation of the International Workshop on Factors of Unsustainability and Overexploitation in Fisheries (Bangkok, Thailand, 4-8 February 2002). FAO Fisheries Reports No. R672, 122 pp.

FAO (2003) Fisheries management. 2. The ecosystem approach to fisheries. FAO Technical Guidelines for Responsible Fisheries No. 4, 112 pp.

Froese, R. (2004) Keep it simple: three indicators to deal with overfishing. Fish and Fisheries 5, 86-91.

Fryer, R.J. and Nicholson, M.D. (1993) The power of a temporal trend monitoring programme to detect linear trends and incidents. ICES Journal of Marine Science 50, 161-168.

Fulton, E.A., Smith, A.D.M., Webb, H. and Slater, J. (2004a) Ecological indicators for the impacts of fishing on non-target species, communities and ecosystems: review of potential indicators. Australian Fisheries Management Authority Final Research Report No. R99/1546, 116 pp.

Fulton, E.A., Fuller, M., Smith, A.D.M. and Punt, A. (2004b) Ecological indicators of the ecosystem effects of fishing: final report. Australian Fisheries Management Authority Final Research Report No. R99/1546, 239 pp.

Fulton, E.A., Smith, A.D.M. and Punt, A.E. (2005) Which ecological indicators can robustly detect effects of fishing? ICES Journal of Marine Science 62, 540-551.

Garcia, S.M. and Staples, D.J. (2000) Sustainability reference systems and indicators for responsible marine capture fisheries: a review of concepts and elements for a set of guidelines. Marine and Freshwater Research 51, 385-426.

Garcia, S.M., Staples, D.J. and Chesson, J. (2000) The FAO guidelines for the development and use of indicators of sustainable development of marine capture fisheries and an Australian example of their application. Ocean and Coastal Management 43, 537-556.

Gerrodette, T. (1987) A power analysis for detecting trends. Ecology 68, 1364-1372.

Gilbert, D.J., Annala, J.H. and Johnston, K. (2000) Technical background to fish stock indicators for stateof-environment reporting in New Zealand. Marine and Freshwater Research 51, 451-464.

Gislason, H. and Sinclair, M.M. (eds) (2000) Ecosystem effects of fishing. ICES Journal of Marine Science 57, 465791.

Hall, S.J. and Mainprize, B. (2004) Towards ecosystembased fisheries management. Fish and Fisheries 5, 1-20.

Hilborn, R. (2004) Ecosystem-based fishery management: the carrot or the stick. Marine Ecology Progress Series 274, 275-278.

Hilborn, R. and Walters, C.J. (1992) Quantitative Fisheries Stock Assessment: Choice, Dynamics and Uncertainty. Chapman and Hall, New York.

ICES (2001) Report of the working group on ecosystem effects of fishing activities. ICES CM 2001, ACME 09, $121 \mathrm{pp}$.

ICES (2003) Report of the working group on ecosystem effects of fishing activities. ICES CM 2003, ACE 05, $193 \mathrm{pp}$.

ICES (2005) Guidance on the application of the ecosystem approach to management of human activities in the European marine environment. ICES Co-operative Research Report No. 273, 22 pp.

Jennings, S. (2004) The ecosystem approach to fishery management: a significant step towards sustainable use of the marine environment? Marine Ecology Progress Series 274, 279-282.

Jennings, S. and Dulvy, N.K. (2005) Reference points and reference directions for size-based indicators of community structure. ICES Journal of Marine Science 62, 397404.

Jennings, S., Greenstreet, S.P.R., Hill, L., Piet, G.J., Pinnegar, J.K. and Warr, K.J. (2002) Long-term trends in the trophic structure of the North Sea fish community: evidence from stable isotope analysis, size-spectra and community metrics. Marine Biology 141, 10851097.

Johannes, R.E. (1998) The case for data-less marine resource management: examples from tropical nearshore finfisheries. Trends in Ecology and Evolution 13, 243-246.

Kaiser, M.J. and de Groot, S.J. (eds) (2000) The Effects of Fishing on Non-target Species and Habitats: Biological, Conservation and Socio-economic Issues. Blackwell Science, Oxford.

Link, J.S. (2002) Ecological considerations in fisheries management: when does it matter? Fisheries 27, 10-17.

Link, J.S. (2005) Translating ecosystem indicators into decision criteria. ICES Journal of Marine Science 62, 569576. 
Link, J.S., Brodziak, J.K.T., Edwards, S.F. et al. (2002) Marine ecosystem assessment in a fisheries management context. Canadian Journal of Fisheries and Aquatic Science 59, 1429-1440.

Maunder, M.N., Starr, P.J. and Hilborn, R. (2000) A Bayesian analysis to estimate loss in squid catch due to the implementation of a sea lion population management plan. Marine Mammal Science 16, 413-426.

Maxwell, D. and Jennings, S. (2005) Power of monitoring programmes to detect decline and recovery of rare and vulnerable fish. Journal of Applied Ecology 42, 25-37.

Mullon, C., Cury, P.M. and Shannon, L.J. (2004) Viability model of trophic interactions. Natural Resource Modelling 17, 27-58.

Murawski, S.A. (2000) Definitions of overfishing from an ecosystem perspective. ICES Journal of Marine Science 57, 649-658.

Myers, R.A., Mertz, G. and Fowlow, P.S. (1997) Maximum population growth rates and recovery times for Atlantic cod Gadus morhua. Fishery Bulletin 95, 762-772.

Nicholson, M.D. and Fryer, R.J. (1992) The statistical power of monitoring programmes. Marine Pollution Bulletin 24, 146-149.

Nicholson, M.D. and Jennings, S. (2004) Testing candidate indicators to support ecosystem-based management: the power of monitoring surveys to detect temporal trends in fish community metrics. ICES Journal of Marine Science 61, 35-42.

O’Boyle, R., Sinclair, M., Keizer, P., Lee, K., Ricard, D. and Yeats, P. (2005) Indicators for ecosystem-based management on the Scotian Shelf: the gap between theory and practice. ICES Journal of Marine Science 62, 598-605.

Patterson, K., Cook, R., Darby, C. et al. (2001) Estimating uncertainty in fish stock assessment and forecasting. Fish and Fisheries 2, 125-157.

Pauly, D. (1995) Anecdotes and the shifting baseline syndrome of fisheries. Trends in Ecology and Evolution 10, 34.

Pauly, D., Christensen, V., Dalsgaard, J., Froese, R. and Torres, F. (1998) Fishing down marine food webs. Science 279, 860-863.

Peterman, R.M. (1990) Statistical power analysis can improve fisheries research and management. Canadian Journal of Fisheries and Aquatic Science 47, 2-15.

Piet, G.J. and Jennings, S. (2005) Response of potential fish community indicators to fishing. ICES Journal of Marine Science 61, 214-225.

Piet, G.J. and Rice, J.C. (2005) Performance of precautionary reference points in providing management advice on North Sea stocks. ICES Journal of Marine Science 61, 1305-1312.

Pikitch, E.K., Santora, C., Babcock, E.A. et al. (2004) Ecosystem-based fishery management. Science $\mathbf{3 0 5}$, 346-347.

Pope, J.G. and Symes, D. (2000) An Ecosystem Based Approach to the Common Fisheries Policy: Defining the Goals. English Nature, Peterborough.
Pope, J.G., MacDonald, D.S., Daan, N., Reynolds, J.D. and Jennings, S. (2000) Gauging the vulnerability of nontarget species to fishing. ICES Journal of Marine Science 57, 689-696.

Pope, J.G., Rice, J.C., Daan, N., Jennings, S. and Gislason, H. (2004) Are the slopes of size spectra a useful tool for measuring the impact of fisheries in multispecies systems?. ICES CM 2004/FF 32, 32 pp.

Punt, A.E., Smith, A.D.M. and Cui, G. (2001) Review of progress in the introduction of management strategy evaluation (MSE) approaches in Australia's south-east fishery. Marine and Freshwater Research 52, 719-726.

Rice, J.C. (2000) Evaluating fishery impacts using metrics of community structure. ICES Journal of Marine Science 57, 682-688.

Rice, J.C. (2003) Environmental health indicators. Ocean and Coastal Management 46, 235-259.

Rice, J.C. and Gislason, H. (1996) Patterns of change in the size spectra of numbers and diversity of the North Sea fish assemblage, as reflected in surveys and models. ICES Journal of Marine Science 53, 1214-1225.

Rice, J.C. and Rochet, M.-J. (2005) A framework for selecting a suite of indicators for fisheries management. ICES Journal of Marine Science 62, 516-527.

Rochet, M.-J. and Trenkel, V.M. (2003) Which community indicators can measure the impact of fishing? a review and proposals. Canadian Journal of Fisheries and Aquatic Science 60, 86-99.

Rogers, S.I. and Greenaway, B. (2005) A UK perspective on the development of marine ecosystem indicators. Marine Pollution Bulletin 50, 9-19.

Rosenburg, A.A. and Restrepo, V. (1994) Uncertainty and risk evaluation in stock assessment advice for U.S. marine fisheries. Canadian Journal of Fisheries and Aquatic Science 51, 2715-2720.

Sainsbury, K. and Sumaila, U.R. (2003) Incorporating ecosystem objectives into management of sustainable marine fisheries, including 'best practice' reference points and use of marine protected areas. In: Responsible Fisheries in the Marine Ecosystem (eds M. Sinclair and G. Valdimarsson). CABI Publishing, Rome, pp. 343-361.

Sainsbury, K.J., Punt, A.E. and Smith, A.D.M. (2000) Design of operational management strategies for achieving fishery ecosystem objectives. ICES Journal of Marine Science 57, 731-741.

Shin, Y.-J., Rochet, M.-J., Jennings, S., Field, J. and Gislason, H. (2005) Using size-based indicators to evaluate the ecosystem effects of fishing. ICES Journal of Marine Science 62, 384-396.

Sinclair, M. and Valdimarsson, G. (eds) (2003) Responsible Fisheries in the Marine Ecosystem. CABI Publishing, Rome.

Smith, S.J., Hunt, J.J. and Rivard, D. (1993) Risk evaluation and biological reference points for fisheries management. Canadian Special Publication of Fisheries and Aquatic Sciences 120, 1-422. 
Spellerberg, I.F. (2005) Monitoring Ecological Change, 2nd edn. Cambridge University Press, Cambridge.

Taylor, B.L. and Gerrodette, T. (1993) The uses of statistical power in conservation biology: the vaquita and northern spotted owl. Conservation Biology 7, 489500.

Trenkel, V.M. and Rochet, M.-J. (2003) Performance of indicators derived from abundance estimates for detecting the impact of fishing on a fish community. Canadian Journal of Fisheries and Aquatic Science 60, 67-85.

Walters, C.J. and Martell, S.J.D. (2004) Fisheries Ecology and Management. Princeton University Press, Princeton and Oxford.

Ward, T.J. (2000) Indicators for assessing the sustainability of Australia's marine ecosystems. Marine and Freshwater Research 51, 435-446.
Weimerskirch, H., Brothers, N. and Jouventin, P. (1997) Population dynamics of wandering albatross Diomedea exulans and Amsterdam albatross D. amsterdamensis in the Indian Ocean and their relationships with long-line fisheries: conservation implications. Biological Conservation 79, 257-270.

Witherell, D., Pautzke, C. and Fluharty, D. (2000) An ecosystem-based approach for Alaska groundfish fisheries. ICES Journal of Marine Science 57, 771-777.

WSSD (2002) Plan of Implementation of the World Summit on Sustainable Development. Division of Sustainable Development, UN Department of Economic and Social Affairs, New York.

Zwanenburg, K.C.T. (2000) The effects of fishing on demersal fish communities of the Scotian shelf. ICES Journal of Marine Science 57, 503-509. 